Int. J. Plant Sci. 172(4):000-000. 2011.

(C) 2011 by The University of Chicago. All rights reserved.

1058-5893/2011/17204-00XX\$15.00 DOI: $10.1086 / 658921$

\title{
ENVIRONMENTAL CONTEXT OF ENDOPHYTE SYMBIOSES: INTERACTING EFFECTS OF WATER STRESS AND INSECT HERBIVORY
}

\author{
M. Isabel Miranda, Marina Omacini, and Enrique J. Chaneton ${ }^{1}$ \\ Instituto de Investigaciones Fisiológicas y Ecológicas Vinculadas a la Agricultura-Consejo Nacional de Investigaciones \\ Científicas y Técnicas (IFEVA-CONICET); and Facultad de Agronomía, Universidad de Buenos Aires, \\ Avenida San Martín 4453, C1417DSE, Buenos Aires, Argentina
}

\begin{abstract}
Symbiotic associations between grasses and fungal endophytes are generally regarded as mutualistic, yet benefits to host plants may vary with environmental context. Previous studies have emphasized how endophytes influence plant responses to single stressors. In contrast, the outcome of endophyte-grass interactions under simultaneous biotic and abiotic stresses remains poorly explored. We hypothesized that benefits from endophyte symbiosis become most apparent in "complex" environments where hosts experience multiple stresses. We evaluated the performance of endophyte-infected (E+) vs. endophyte-uninfected (E-) Lolium multiflorum plants in a factorial experiment with water supply (control vs. drought) and insect herbivory (with aphids vs. without aphids). Endophyte infection delayed tiller production in well-watered plants, while water stress reduced tillering in E- plants. Endophyte mediation of herbivory tolerance was contingent on water supply. Whereas aphid herbivory was detrimental to E+ plants in well-watered soils, aphids interacted with drought stress in decreasing the reproductive output of E- but not E+ plants. Moreover, endophyte presence decreased aphid densities on drought-stressed plants only. Thus, endophyte symbiosis enhanced host tolerance to overlapping biotic and abiotic stresses, although infected plants failed to outgrow their uninfected counterparts. These results support the view that mutualistic endophyte effects may not arise in low-stress environments.
\end{abstract}

Keywords: drought, grass-endophyte interaction, herbivore resistance, multiple stresses, mutualism, protective symbiont.

\section{Introduction}

Evolved associations with microbial endosymbionts help plants to cope with a variety of abiotic and biotic stresses (Smith and Read 1997; Arnold et al. 2003; Saikkonen et al. 2004; White and Torres 2009). The ecological consequences of symbiosis, however, occur along a continuum from mutualism to parasitism, as the interaction can be beneficial, neutral, or detrimental to the host depending on environmental context (Bronstein 1994; Johnson et al. 1997; Saikkonen et al. 1998; Hoeksema and Bruna 2000). Many temperate grasses form lifelong associations with vertically transmitted fungal endophytes (Clay and Schardl 2002; Rodriguez et al. 2009). The proposed mutualistic nature of these symbioses has recently come under intense scrutiny due to varying endophyte effects on host performance in different settings (for a review, see Cheplick and Faeth 2009). Interacting environmental factors, such as water stress and consumer pressure, may either enhance the benefits of symbiosis or exacerbate the costs to the plant of hosting the symbiont (Bronstein 1994; Saikkonen et al. 1998; Müller and Krauss 2005). Still, few studies have examined endophyte-grass interactions in multiple-stress contexts (Bultman and Bell 2003; Lehtonen et al. 2005; Saona et al. 2010).

1 Author for correspondence; e-mail: chaneton@ifeva.edu.ar.

Manuscript received October 2010; revised manuscript received November 2010.
Seed-borne, asexual endophytic fungi of the genus Neotyphodium (Clavicipitaceae, Balansiae) grow asymptomatically in the apoplast of stem and leaf tissues, where they take up carbohydrates and nutrients acquired by the host grass (class 1, type III endophytes; Rodriguez et al. 2009). Fungal hyphae colonize flowering culms during plant maturation, and this results in the vertical transmission of the endophyte across generations through host seeds. Since Neotyphodium endophytes have lost the capacity for sexual reproduction, their long-term persistence depends entirely on the host's fitness (Clay and Schardl 2002; Saikkonen et al. 2004). These hereditary symbioses have generally been regarded as mutualisms (Clay and Schardl 2002; Rudgers et al. 2010), although benefits to the host are frequently indirect and are not always clear (Müller and Krauss 2005; Cheplick and Faeth 2009). The net outcome for the plant can be understood as the sum of positive and negative endophyte effects, the balance of which is contingent on prevailing conditions (Saikkonen et al. 1998; Saona et al. 2010). Mutualistic endophyte effects often involve enhanced host performance under abiotic or biotic stress (Malinowski and Belesky 2000; Clay and Schardl 2002; Kuldau and Bacon 2008). Instead, antagonistic effects may be common in the absence of specific stressors (Clay et al. 1993; Rodriguez et al. 2009) and in certain grass-endophyte associations (Faeth and Sullivan 2003).

Host protection against insect herbivory has been widely cited as a benefit of endophyte symbiosis (Breen 1994; Faeth 2002; White and Torres 2009). Infected plants produce 
alkaloids that are toxic to many folivorous taxa (Dahlman et al. 1991; Bush et al. 1997). Yet endophyte-induced insect resistance is not universal, especially in grass species with low or variable alkaloid levels (Saikkonen et al. 1998; Faeth 2002; Krauss et al. 2007). Further, whereas most studies have focused on insect responses to endophyte presence (i.e., herbivory resistance; Breen 1994; Faeth and Bultman 2002), less attention has been given to herbivore impacts on relative host fitness (i.e., herbivory tolerance; Wise and Abrahamson 2005; but see Clay et al. 1993; Bultman et al. 2004). On the other hand, fungal endophytes often increase host tolerance to water stress. Infected plants can exhibit higher water-use efficiency, growth, or survivorship than endophyte-free plants under drought conditions (Arachevaleta et al. 1989; West et al. 1993; Morse et al. 2002; Kannadan and Rudgers 2008; Swarthout et al. 2009). It has been found, however, that the costs of symbiosis may sometimes exceed its benefits when host plants grow under severe water limitation (Eerens et al. 1998; Ahlholm et al. 2002; Cheplick 2007).

Work on endophyte-grass symbioses has emphasized plant responses to single stressors. In natural settings, however, perceived endophyte effects may be contingent on interacting environmental factors (Lehtonen et al. 2005; Saona et al. 2010). Specifically, little is known about how endophytemediated responses to insect herbivory are modulated by water stress (Bultman and Bell 2003). Plant defense theory predicts that drought-stressed plants should allocate more resources to the production of secondary metabolites that act as herbivore deterrents (Herms and Mattson 1992). Likewise, herbivory tolerance is expected to vary with resource availability to focal plants (Wise and Abrahamson 2005). Drought stress has been found to increase alkaloid concentrations (Arachevaleta et al. 1989; Eerens et al. 1998; Hahna et al. 2008) and herbivore resistance (Bultman and Bell 2003) in some endophytic grasses. Yet it is unclear to which extent the endophyte mediation of grass-insect interactions depends on water supply and, reciprocally, whether drought tolerance in infected plants varies with herbivore pressure.

Here we examine the interactive effects of drought stress and insect herbivory on the outcome of a fungal endophyteannual grass symbiosis. We tested the hypothesis that benefits of symbiosis become more apparent in "complex" environments in which host plants are exposed to both biotic and abiotic stressors. In general, differential responses of endophyte-infected $(\mathrm{E}+)$ and endophyte-uninfected $(\mathrm{E}-)$ plants to stress factors should be revealed by the interaction of endophyte infection with stress level. We considered two aspects of this interaction. First, we tested whether performance of E+ versus E- plants shifted among no stress, singlestress, and multiple-stress environments. Additionally, we assessed how a given stressor altered performance of each plant type $(\mathrm{E}+$ and $\mathrm{E}-$ ) relative to the control (nonstress) condition. The former reflects endophyte impact on host fitness in different contexts, and it has usually been considered when evaluating the nature of the symbiosis (Gundel et al. 2008; Cheplick and Faeth 2009). In contrast, the latter considers how infection status affects a plant's ability to tolerate a specific stressor. E+ and E- plants of Lolium multiflorum Lam. were subjected to drought stress and aphid herbivory in a greenhouse factorial experiment. We measured host plant growth and reproductive output in each condition and monitored aphid colony dynamics on $\mathrm{E}+$ and $\mathrm{E}-$ plants to assess their differential resistance to herbivory.

\section{Material and Methods}

\section{Study System}

Lolium multiflorum (Italian ryegrass) is a $\mathrm{C}_{3}$ annual grass species that is widely naturalized in temperate regions, where it is often grown for livestock grazing. The species is also a major component of seminatural grasslands and pastures in the Argentine Pampas, where the original seed material for this study was collected. Pampean ryegrass populations usually bear high rates $(>85 \%)$ of endophyte infection (de Battista et al. 1997), presumably by Neotyphodium occultans (Moon et al. 2000; Sugawara et al. 2006). This endophyte-grass symbiota produces "loline" alkaloids (Omacini et al. 2009), which provide resistance against foliar insects (Omacini et al. 2001). It does not contain the extraordinary levels of alkaloids found in some perennial pasture grasses (TePaske et al. 1993), thus increasing comparability with other systems (Faeth 2002). Endophyte-infected L. multiflorum plants also synthesize various phenolic compounds of yet-unknown function that are not found in endophyte-free plants (Ponce et al. 2009). Infected plants often perform better than uninfected conspecifics (Vila-Aiub et al. 2005; Uchitel et al. 2011), but responses of E+ annual ryegrass to water supply compared with responses of $\mathrm{E}-$ annual ryegrass have not been studied.

\section{Experimental Design}

We conducted a $2 \times 2 \times 2$ factorial experiment, with endophyte infection, water supply, and insect herbivory as the main factors in a blocked, split-plot design. Plants were grown from seed in 3-L pots (three plants per pot) filled with a nutrient-rich organic soil mix that were grouped in eight blocks of eight pots, for a total of 64 experimental units. Each pot in a block was randomly assigned one level of each of the following factors: (1) endophyte: seeds with high $(\mathrm{E}+)$ or low (E-) endophyte incidence; (2) water supply: low $(\mathrm{W}-)$ or high $(\mathrm{W}+)$ watering regime; and (3) herbivory: with $(\mathrm{A}+)$ or without $(\mathrm{A}-)$ aphids. The spatial arrangement of the pots in the greenhouse was such that those receiving endophyte and water treatments (subplots) were nested within levels of those receiving the aphid treatment (main plot). The experiment was run between mid-autumn and early summer (May-December), comprising the main growing season of $L$. multiflorum at the study latitude. Plants were grown under ambient light conditions throughout the study period and received no nutritional supplementation.

Seeds with high $(>98 \%)$ and low $(<9 \%)$ endophyte infection rates were obtained from monocultures maintained at the College of Agronomy, University of Buenos Aires, Argentina $\left(34^{\circ} 35^{\prime} \mathrm{S}, 58^{\circ} 35^{\prime} \mathrm{W}\right)$. Seeds were originally collected from natural populations with $\sim 95 \%$ Neotyphodium infec- Q1 tion in old-field communities of the Inland Pampa, Argentina (Omacini et al. 2009). E- seeds were obtained by treating sets of E+ seeds with the systemic fungicide Baytan (Bayer 
CropScience). These initial E+ and E- lines were propagated separately over a period of $3 \mathrm{yr}$ in monocultures grown in a common garden under natural weather conditions. Plants were allowed to cross-pollinate freely, which contributed to the homogenization of the plants' genetic background relative to the endophyte treatment. Seeds used in this study were three generations removed from the original, which minimized potential side effects from the fungicide (Cheplick and Faeth 2009). Since we used large seed pools drawn at random from wild populations, observed differences between $\mathrm{E}+$ and $\mathrm{E}-$ plants would reflect average endophyte effects, irrespective of host plant genotype (Uchitel et al. 2011).

Plants were allowed to establish for 2.5 mo before the watering treatments were initiated in early spring (October), after $77 \mathrm{~d}$ of the experiment had elapsed. During this early period, all pots were watered to field capacity. The gravimetric soil moisture content of $\mathrm{W}+$ pots was maintained at $40 \%-$ $60 \%$ of their total dry mass by watering five times per week. To create a moderate drought condition, the soil water content of $\mathrm{W}-$ pots was reduced to about one-half of the level $(15 \%-30 \%)$ recorded in $\mathrm{W}+$ pots, for the remainder of the experiment. Soil water content of the $\mathrm{W}+$ pots and of the $\mathrm{W}$ - pots were adjusted on a daily basis, using eight additional pots per treatment for which the total dry mass had been calibrated for changes in gravimetric soil water content. These control pots were identical to the experimental ones and were interspersed among the aphid-free pots in each block. Soil volumetric water content was measured one time at the end of the experiment, using a ThetaProbe sensor (Delta-T Devices, Cambridge). Mean water content ( $\%$ [volume of water/volume of soil]) was nearly twice as high in $\mathrm{W}+$ pots $(18.9 \% \pm 1.3 \%)$ as it was in $\mathrm{W}-$ pots $(10.7 \% \pm 0.3 \%)$. Plant water status was monitored every fortnight (six dates) during the vegetative growth phase (before aphid addition), by measuring leaf water potential with a pressure bomb in one $\mathrm{E}+$ plant and one $\mathrm{E}-$ plant (using one fully expanded leaf per plant) from the $\mathrm{W}+$ and the $\mathrm{W}-$ pots in each block. Mean leaf water potentials were $-0.73 \pm 0.03 \mathrm{MPa}$ for $\mathrm{W}+$ plants and $-1.25 \pm 0.04 \mathrm{MPa}$ for $\mathrm{W}$ - plants $(P<0.001)$. No significant difference in leaf water status was found between $\mathrm{E}+$ plants and $\mathrm{E}-$ plants $(P>0.10)$.

In November (spring), after $127 \mathrm{~d}$ of study, one-half of the pots in each block were sown with 10 individuals (two adults + eight nymphs) of Sipha maydis, a common introduced grass aphid in Argentina. Colonies of S. maydis were reared on young Bromus catharticus plants, an endophyte-free native grass. In addition, plants were naturally colonized by bird cherry-oat aphids (Rhopalosiphum padi), which are also frequently found on Italian ryegrass (Omacini et al. 2001). Rhopalosiphum padi aphids were removed only from control, aphid-free plants, and therefore they became integral to the herbivory treatment. In each block, aphid-infested pots $(\mathrm{A}+)$ were enclosed by a muslin cage $(55 \mathrm{~cm} \times 70 \mathrm{~cm} \times 110$ $\mathrm{cm})$. Aphid-free $(\mathrm{A}-)$ pots were caged in the same manner and were regularly checked for aphid removal. Both aphid species occurred in all A+ plants, but they occupied different positions, with $S$. maydis located in the lower leaves and $R$. padi feeding on higher leaves and flowering culms. We found no correlation between aphid species densities per plant throughout the study $(r<0.05, P>0.10)$. Mean daily temperatures $( \pm \mathrm{SE})$ were $19.3^{\circ} \pm 1.3^{\circ} \mathrm{C}$ inside the cages and $23.7^{\circ} \pm 1.3^{\circ} \mathrm{C}$ outside the cages. Cages reduced photosynthetic photon flux density (PPFD) by $30 \%$ relative to ambient levels. Mean midday PPFD levels (late spring) inside and outside the cages were $\sim 1100$ and $1500 \mu \mathrm{mol} \mathrm{m} \mathrm{m}^{-2} \mathrm{~s}^{-1}$, respectively. Such a decrease in light availability has little influence on grass-endophyte interactions (Davitt et al. 2010).

\section{Plant and Insect Measurements}

Plant growth was monitored at 2-3-wk intervals during the spring (October-December), after imposing the watering treatments and before and after initiating the aphid treatments. On each census date, we counted the number of vegetative tillers and flowering culms in each of the plants; the latter was used as a proxy of reproductive output. In addition, leaf number and tiller length were measured for two randomly selected reproductive tillers in each plant per pot. In late December, when plants reached reproductive maturity and seeds were still attached to the plant (but had not fully ripened), all aboveground biomass was harvested, sorted into vegetative and reproductive parts, oven-dried at $70^{\circ} \mathrm{C}$, and weighed. Mean seed mass was calculated from 100-seed samples collected from each pot. Total root mass was measured by taking a $3-\mathrm{cm}$-diameter soil core from the center of each pot. Roots were gently washed, oven-dried, and weighed. Leaf nitrogen $(\mathrm{N})$ and phosphorous $(\mathrm{P})$ concentrations were measured using standard digestion methods for pooled samples of 15 leaves per pot (five leaves per plant) collected before (November) and after (December) plant flowering.

Aphid densities were monitored every $3-5 \mathrm{~d}$ by counting all adults and nymphs of each aphid species in all three plants in each pot (eight census dates). Even though we periodically removed other insects, as well as any aphids occurring on the A- plants, two blocks had to be dropped from the analyses because predators wiped out aphid colonies (personal observa- Q2 tion). Thus, aphid density statistics are shown for six blocks.

At the end of the experiment, we checked for endophyte infection of $\mathrm{E}+$ and $\mathrm{E}$ - plants by microscopic examination of 20 seeds per pot (Moon et al. 2000). Final frequency of Neotyphodium infection for E+ and E- plants averaged $75.7 \%$ and $3.3 \%$, respectively. No significant differences in endophyte incidence were found across the water or the aphid treatments $(P>0.10)$.

\section{Statistical Analysis}

Numbers of vegetative tillers and flowering culms were analyzed using repeated-measures ANOVA (rmANOVA). To enhance interpretation, data collected before and after the addition of aphids were included in separate analyses, coinciding with the main vegetative and reproductive growth phases of the plants, respectively. Data collected before aphid addition (vegetative phase) were examined with rmANOVA, using endophyte infection and water supply as betweensubjects effects ( $n=16$ blocks) and the census date as the within-subjects effect (three dates). Data collected after aphid addition (reproductive phase) were tested with split-plot rmANOVA (two dates) including the aphid treatment as the main plot effect and endophyte infection and water supply as subplot effects ( $n=8$ blocks). Plant variables measured at the 
end of the experiment were examined with split-plot ANOVA. Where appropriate, treatment means were separated with least Q3 significant difference tests $(P<0.05)$.

Aphid numbers were analyzed separately for each species, using rmANOVA with endophyte and water supply as betweensubjects effects and census date as a within-subjects effect ( $n=6$ blocks). For $R$. padi, the initial two censuses included too many zero values and so were excluded, leaving six dates for analysis (eight dates for $S$. maydis). Aphid counts were transformed to $\ln (x+1)$ before analysis. Aphid population dynamics were summarized by calculating per-capita population growth rates from a simple exponential model describing the changes in aphid densities over the time course of the experiment on each plant. All analyses were performed using STATISTICA software (Statsoft).

\section{Results}

During the early growth phase of the experiment (before aphid addition), endophyte infection reduced mean tiller number per plant (rmANOVA: $F_{1,21}=108.7, P=0.0001$ ), and this effect was stronger in well-watered plants than in drought-stressed plants (endophyte $\times$ water: $F_{1,21}=22.38$, $P=0.0001$; fig. 1a). Drought decreased tiller production in E- plants $\left(F_{1,21}=21.04, P=0.0002\right)$ but did not affect vegetative growth in $\mathrm{E}+$ plants (fig. $1 a$ ).

During the reproductive growth phase, drought similarly reduced vegetative tiller (table 1; fig. $1 a$ ) and flowering culm production (fig. $1 b$ ) in both $\mathrm{E}-$ and $\mathrm{E}+$ plants. Aphid herbivory also exerted a negative yet transient effect on vegetative tillering in $\mathrm{E}+$ and $\mathrm{E}-$ plants (rmANOVA: herbivory $\times$ time, $P<0.001)$. The endophyte effect on early vegetative growth disappeared with plant development after aphid addition (endophyte $\times$ time, $P=0.0001$; fig. $1 a$ ), but it was reflected in the number of flowering culms produced by $\mathrm{E}+$ plants relative to that produced by $\mathrm{E}$ - plants. On average, endophyte infection generally decreased flowering culm production (table 1; fig. 1b). More importantly, however, aphid herbivory significantly interacted with endophyte presence and drought stress in determining the number of flowering culms (table 1). In the absence of aphids, endophyte infection and drought stress had no significant impact on reproductive output (fig. 2). In contrast, endophyte presence decreased the flowering culm production of aphid-infested plants under well-watered conditions. Furthermore, the combination of aphid herbivory and drought stress reduced reproductive output in E- plants, whereas no such effect was found in E+ plants (fig. 2).

At harvest, and regardless of endophyte status, water stress decreased mean leaf number, tiller length, and total shoot biomass, thus increasing the root : shoot biomass ratio (table 2; fig. 3). Drought reduced vegetative tiller biomass $(3.04 \pm 0.14$ vs. $\left.2.25 \pm 0.11 \mathrm{~g} \mathrm{plant}^{-1}\right)$ more strongly than it reduced reproductive biomass $\left(0.82 \pm 0.06\right.$ vs. $0.67 \pm 0.05$ g plant $\left.^{-1}\right)$. Thus, water-stressed plants allocated more shoot biomass to reproductive organs than did well-watered plants $(0.32 \mathrm{~g}$ vs. 0.26 g; table 2). Endophyte infection did not substantially al- Q4 ter host biomass growth, although shoot biomass was marginally lower in $\mathrm{E}+$ plants than in $\mathrm{E}-$ plants $(P<0.11$; table 2; fig. $3 b$ ). This resulted in $\mathrm{E}+$ plants having increased biomass allocation to roots compared with to shoots (fig. $3 c$ ).

\section{$\mathrm{O} E-\mathrm{W}+\Delta \mathrm{E}-\mathrm{W}-\mathrm{OE}+\mathrm{W}+\Delta \mathrm{E}+\mathrm{W}-$}

(a) Vegetative tillers

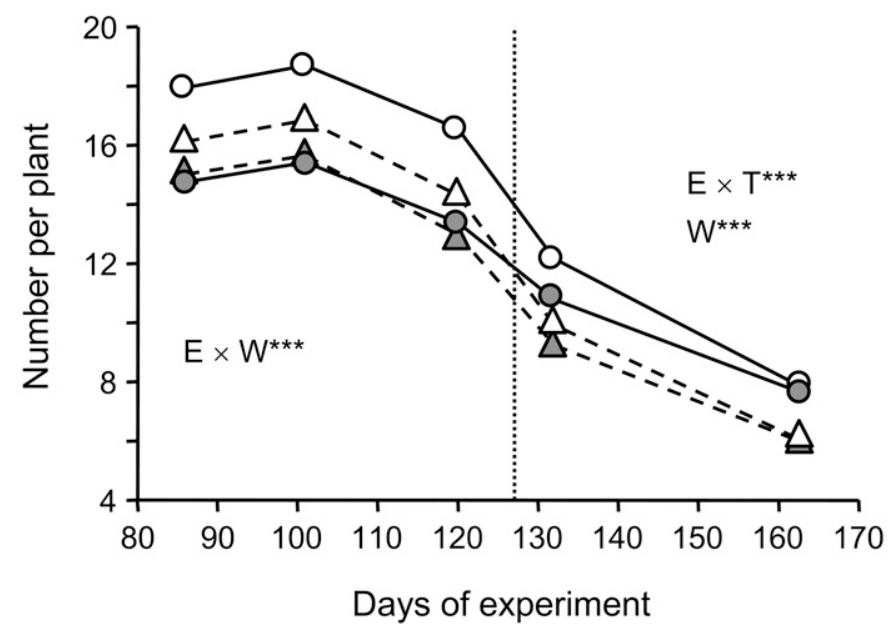

(b) Flowering culms

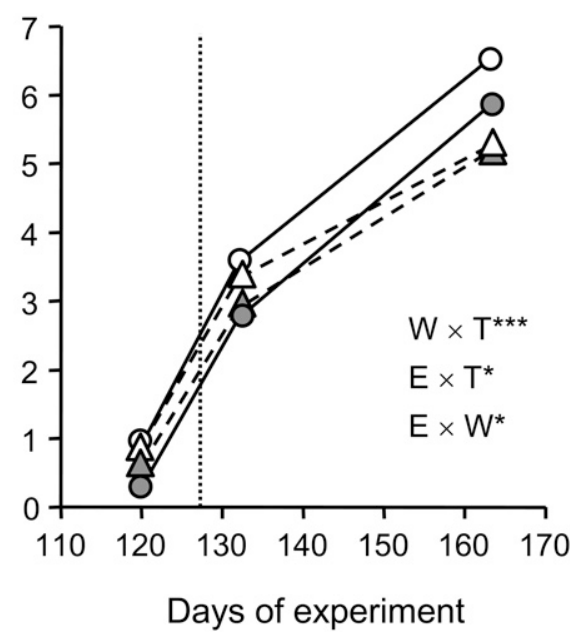

Fig. 1 Tillering dynamics of endophyte-infected $(E+)$ and endophyte-uninfected $(E-)$ Lolium multiflorum plants growing under well-watered $(W+)$ and drought $\left(W_{-}\right)$conditions. Data show the mean number of vegetative tillers $(a)$ and the flowering culms per plant $(b)$, pooled over aphid treatments (error bars omitted for clarity). The dotted vertical line marks the initiation of the aphid herbivory treatment. Asterisks denote significant endophyte $(E)$, water $(W)$, and time $(T)$ effects: three asterisks indicate $P<0.001$, two asterisks indicate $P<0.01$, and one asterisk indicates $P<0.05$. 
Table 1

ANOVA of the Effects of Aphid Herbivory, Endophyte Infection, and Water Supply on Lolium multiflorum Performance during the Reproductive Phase of the Experiment

\begin{tabular}{|c|c|c|c|c|c|}
\hline \multirow[b]{2}{*}{ Source } & \multirow[b]{2}{*}{ df } & \multicolumn{3}{|c|}{ Vegetative tillers } & \multirow{2}{*}{$\frac{\text { Flowering culms }}{P}$} \\
\hline & & $F$ & $P$ & $F$ & \\
\hline \multicolumn{6}{|l|}{ Between subjects: } \\
\hline Aphids (A) & 1,7 & 3.22 & .116 & 4.77 & .0653 \\
\hline Endophyte (E) & 1,42 & 242.53 & .0001 & 28.69 & .0001 \\
\hline Water supply (W) & 1,42 & 24.76 & .0001 & 31.69 & .0001 \\
\hline $\mathrm{E} \times \mathrm{W}$ & 1,42 & 3.33 & .0752 & 6.46 & .0148 \\
\hline $\mathrm{E} \times \mathrm{A}$ & 1,42 & 1.23 & .274 & .66 & .421 \\
\hline $\mathrm{W} \times \mathrm{A}$ & 1,42 & .93 & .341 & 1.18 & .284 \\
\hline $\mathrm{E} \times \mathrm{W} \times \mathrm{A}$ & 1,42 & .01 & .921 & 26.78 & .0001 \\
\hline \multicolumn{6}{|l|}{ Within subjects: } \\
\hline Time $(\mathrm{T})$ & 1,57 & 1661.15 & .0001 & 2291.36 & .0001 \\
\hline $\mathrm{E} \times \mathrm{T}$ & 1,57 & 25.42 & .0001 & 6.30 & .0149 \\
\hline $\mathrm{W} \times \mathrm{T}$ & 1,57 & .94 & .336 & 80.02 & .0001 \\
\hline $\mathrm{A} \times \mathrm{T}$ & 1,57 & 15.46 & .0002 & 1.57 & .215 \\
\hline $\mathrm{E} \times \mathrm{W} \times \mathrm{T}$ & 1,57 & 2.33 & .132 & 1.57 & .215 \\
\hline $\mathrm{E} \times \mathrm{A} \times \mathrm{T}$ & 1,57 & .10 & .753 & .02 & .888 \\
\hline $\mathrm{W} \times \mathrm{A} \times \mathrm{T}$ & 1,57 & .02 & .888 & .88 & .352 \\
\hline
\end{tabular}

Note. Data were analyzed using split-plot, repeated-measures ANOVA. Significant effects are shown in bold type $(P<0.05)$.

Aphid herbivory did not significantly affect any biomass compartment (table 2). Still, aphid-infested plants tended to produce smaller seeds $(1.66 \pm 0.07$ vs. $1.90 \pm 0.08 \mathrm{mg}$ seed $^{-1}$; split-plot ANOVA: $\left.F_{1,7}=3.66, P=0.097\right)$ and allocate less biomass to reproductive organs $(0.27 \mathrm{~g}$ vs. $0.32 \mathrm{~g}$; $\left.F_{1,7}=4.39, P=0.074\right)$ than aphid-free plants, irrespective of endophyte and water status.

Densities of both aphid species increased exponentially over time. Aphid population responses to endophyte presence and water supply depended on the species. Population growth rates for $R$. padi, the most abundant aphid, were significantly higher on $\mathrm{E}-$ plants $\left(15.24 \pm 3.63 \mathrm{day}^{-1}\right)$ than on $\mathrm{E}+$ plants (2.54 \pm 0.84 day $\left.^{-1} ; F_{1,15}=17.99, P=0.001\right)$. Thus, endophyte infection reduced $R$. padi mean density $\left(F_{1,15}=9.98\right.$, $P=0.0065)$, and this effect strengthened with time as aphid

Q5 population size overshot on $\mathrm{E}-$ plants (endophyte $\times$ date: $F_{5,100}=5.5, P=0.00016$; fig. $4 a$ ). Furthermore, the magnitude of the endophyte effect on $R$. padi depended on soil water supply (endophyte $\times$ water: $F_{1,15}=5.04, P=0.04$ ). Aphid densities were the lowest on $\mathrm{E}+$ plants with a low water supply, whereas aphid numbers on E- plants were not affected by watering (fig. $4 b$ ). Densities of $S$. maydis were not significantly altered by endophyte presence or water supply for most of the experiment (main effects: $P>0.10$; fig. $4 c$ ). However, endophyte infection reduced mean densities of $S$. maydis on drought-stressed plants but not on well-watered plants (endophyte $\times$ water: $F_{1,15}=3.21, P=0.093$; fig. $4 d$ ).

Leaf $\mathrm{N}$ and $\mathrm{P}$ levels were not consistently affected by endophyte infection or water supply. Lack of material precluded inclusion of aphid treatments in these analyses. Foliar $\mathrm{N}$ ranged from $1.19 \%( \pm 0.06 \%)$ to $1.27 \%( \pm 0.05 \%)$ before flowering and from $1.02 \%( \pm 0.07 \%)$ to $1.11 \%( \pm 0.07 \%)$ after flowering (all $P>0.10$ ). Foliar $\mathrm{P}$ levels before flowering were slightly higher in $\mathrm{E}+$ plants $(0.344 \% \pm 0.021 \%)$ than in
E- plants $\left(0.320 \% \pm 0.018 \% ; F_{1,45}=3.98, P=0.052\right)$, and they were marginally lowered by drought (for W+ plants, $0.343 \% \pm 0.019 \%$ vs. for $\mathrm{W}-$ plants, $0.321 \% \pm 0.02 \%$; $F_{1,45}=2.99, P=0.09$ ). However, these trends disappeared for flowering plants, in which $P$ contents ranged from $0.296 \%$ $( \pm 0.037 \%)$ to $0.334 \%( \pm 0.041 \% ; P>0.10)$.

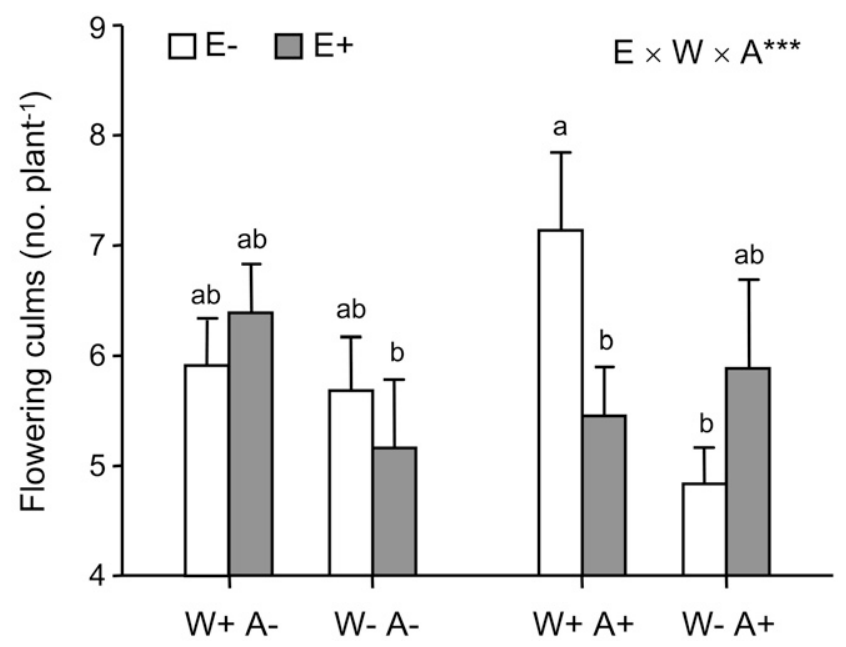

Fig. 2 Interactive effects of water supply and aphid herbivory on the number of flowering culms in endophyte-infected $(E+)$ and endophyte-uninfected $(E-)$ Lolium multiflorum. Bars indicate means $+1 \mathrm{SE}$ for aphid-free $(A-)$ and aphid-infested $(A+)$ plants growing under well-watered $(W+)$ and drought $\left(W_{-}\right)$conditions. Different lowercase letters denote significant differences among treatments $(P<0.05$, least significant difference). Three-way interaction: three asterisks indicate $P<0.001$. 
Table 2

Effects of Endophyte Infection (E), Water Supply (W), and Aphid Herbivory (A) on Lolium multiflorum Growth Performance at the End of the Experiment

\begin{tabular}{|c|c|c|c|c|c|c|c|}
\hline Plant variable & $\mathrm{A}(\mathrm{df}=1,7)$ & $\mathrm{W}(\mathrm{df}=1,42)$ & $\mathrm{E}(\mathrm{df}=1,42)$ & $\begin{array}{c}\mathrm{W} \times \mathrm{E} \\
(\mathrm{df}=1,42)\end{array}$ & $\begin{array}{c}\mathrm{A} \times \mathrm{E} \\
(\mathrm{df}=1,42)\end{array}$ & $\begin{array}{c}\mathrm{A} \times \mathrm{W} \\
(\mathrm{df}=1,42)\end{array}$ & $\begin{array}{l}\mathrm{A} \times \mathrm{W} \times \mathrm{E} \\
(\mathrm{df}=1,42)\end{array}$ \\
\hline Leaf number (no. tiller ${ }^{-1}$ ) & .15 & $31.1^{* * * *}$ & 1.13 & 1.11 & 2.07 & $<.01$ & .26 \\
\hline Mean tiller length $(\mathrm{cm})$ & .46 & $9.39^{* *}$ & $<.01$ & .01 & .01 & .19 & 1.03 \\
\hline Total biomass (g) & 1.05 & $24.90^{* * *}$ & 2.41 & $<.01$ & 1.21 & .34 & $<.01$ \\
\hline Shoot biomass (g) & 1.08 & $24.18^{* * *}$ & 2.74 & $<.01$ & 1.08 & .28 & $<.01$ \\
\hline Vegetative biomass (g) & 2.16 & $30.4^{* * * *}$ & 2.60 & .01 & 1.73 & .43 & .26 \\
\hline Reproductive biomass (g) & .63 & $4.94^{*}$ & 1.38 & .01 & .12 & $<.01$ & .99 \\
\hline Root biomass (g) & .04 & 1.04 & 1.30 & $<.01$ & .03 & 2.91 & .40 \\
\hline $\begin{array}{l}\text { Reproductive biomass:vegetative } \\
\text { biomass }\end{array}$ & 4.39 & $8.13^{* *}$ & .02 & .02 & $<.01$ & 1.07 & .82 \\
\hline Root : shoot & .10 & $8.43^{* * *}$ & $5.09^{*}$ & .12 & .95 & .37 & .89 \\
\hline
\end{tabular}

Note. Values are $F$ ratios from split-plot ANOVA.

"*** $P<0.001$.

"* $P<0.01$

${ }^{*} P<0.05$.

\section{Discussion}

We tested the hypothesis that endophyte symbiosis becomes most beneficial to host plants when these are exposed to combined biotic and abiotic stresses. Overall, results provided partial support to this proposition. Endophyte effects ranged from slightly negative to neutral, as infected plants did not perform better than their uninfected counterparts under single-stress or multiple-stress conditions (figs. 1-3). We found, however, that water stress and insect herbivory interacted in decreasing the reproductive output of $\mathrm{E}$ - plants but not $\mathrm{E}+$ plants. Moreover, aphid densities were reduced by endophyte infection in drought-stressed plants only. Thus, in the presence of aphids, drought shifted the outcome of symbiosis from antagonism to commensalism. These findings show that benefits of endosymbiosis may arise in complex environments through enhanced host tolerance to interacting

Q6 biotic and abiotic stressors (cf. Saona et al. 2010).

\section{Endophyte-Mediated Responses to Drought Stress}

Infection status interacted with drought stress to determine vegetative growth as well as reproductive output of $L$. multiflorum. Endophyte infection reduced tillering, but only in well-watered plants (fig. 1). Other studies have reported antagonistic effects of fungal endophytes, both in cultivated (Eerens et al. 1998; Hesse et al. 2005; Hahna et al. 2008) and native grass species (Morse et al. 2002; Faeth and Sullivan 2003). This is consistent with the notion that harboring a systemic endophyte may represent a net cost in the absence of certain stressors (Rodriguez et al. 2009). Nevertheless, tillering differences between $\mathrm{E}+$ and $\mathrm{E}-$ plants were transient and did not influence final biomass, suggesting that endophytes delayed shoot development under favorable moisture conditions.

Water supply strongly influenced plant growth throughout the experiment. In general, drought was equally detrimental to $\mathrm{E}+$ and $\mathrm{E}-$ plants (table 2; figs. 1, 3). We found that endophyte symbiosis ameliorated the negative impact of drought stress only on early tillering rates (fig. 1a). While endophyte presence did not modify leaf water status (cf. Morse et al. Q7 2002), E+ plants showed higher root : shoot ratios than did E- plants, and this pattern was reported for both annual and perennial Lolium species (Hesse et al. 2005; Vila-Aiub et al. 2005). A lowered shoot biomass (fig. 3) and/or an increased allocation to root growth may allow $\mathrm{E}+$ plants to better withstand soil water deficits (Malinowski and Belesky 2000; Hesse et al. 2005). Nevertheless, benefits from this early protection apparently did not outweigh the costs of infection (Cheplick et al. 2000; Ahlholm et al. 2002). Thus, no clear growth advantage occurred for $\mathrm{E}+$ relative to $\mathrm{E}-$ plants under drought conditions.

\section{Endophyte-Mediated Resistance to Insect Herbivory}

We found that endophyte-mediated resistance to aphid herbivory was conditional on soil water supply. Endophyte infection mostly decreased aphid numbers on drought-stressed plants, a pattern largely driven by the dynamics of $R$. padi (fig. 4), a species known to be highly sensitive to fungal alkaloids (Dahlman et al. 1991). The other aphid, S. maydis, was less responsive to treatments, although the trend was also for smaller colonies on water-stressed E+ plants (fig. 4c, 4d). Aphid species often show differential susceptibility to endophytes, even when feeding on the same host grass (Dahlman et al. 1991; Omacini et al. 2001; Meister et al. 2006). To our knowledge, only two previous studies tested how soil resources affected endophyte-mediated defenses against insect herbivores (Bultman and Bell 2003; Lehtonen et al. 2005). Bultman and Bell (2003) reported a similar synergistic interaction between endophyte and drought stress. Yet they evaluated only short-term $(4 \mathrm{~d})$ changes in reproduction of $R$. padi individuals confined on Lolium arundinaceum (tall fescue) in "clip bags." In our study, the two aphids established successfully in all treatments (fig. $4 a, 4 c$ ); thus, aphid population dynamics were likely determined by differences in vital rates, and not colonization. Both adult aphid survival and fecundity could be reduced on endophyte-infected plants (Bultman and Bell 2003; Meister et al. 2006). 


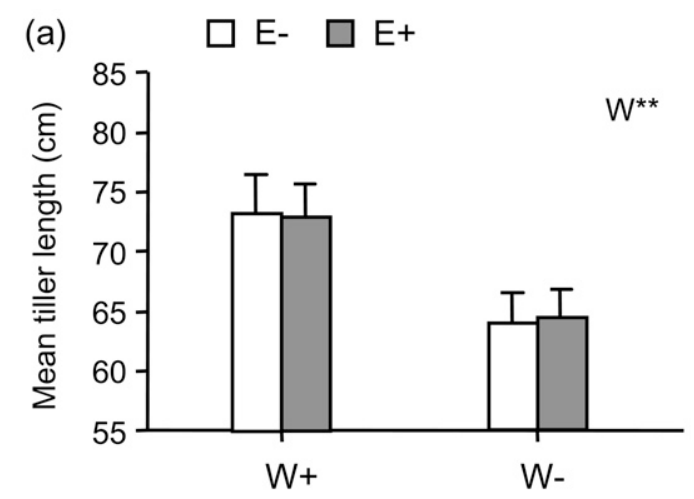

(b)

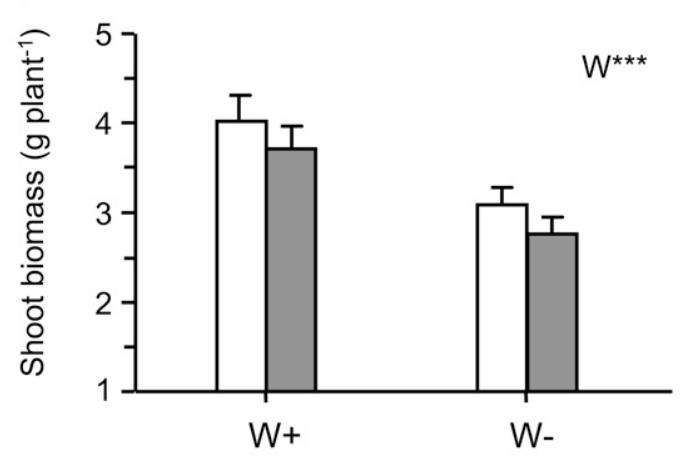

(c)

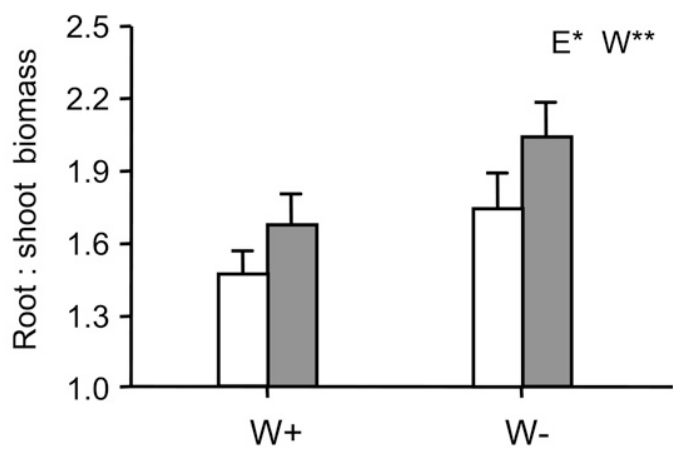

Fig. 3 Effects of endophyte and water supply on mean tiller length $(a)$, shoot biomass $(b)$, and root : shoot ratio $(c)$ of Lolium multiflorum at the end of the experiment. Bars indicate means + SE for endophyteinfected $(E+)$ and endophyte-uninfected $(E-)$ plants under wellwatered $(W+)$ and drought $(W-)$ conditions. Endophyte $(E)$ and water $(W)$ effects: three asterisks indicate $P<0.001$, two asterisks indicate $P<0.01$, and one asterisk indicates $P<0.05$.

The fact that aphid resistance increased in only endophyte-infected plants exposed to a low water supply suggests a role for endosymbionts in modulating herbivore pressure across environmental gradients (Hartley and Gange 2009). Interestingly, the form of this endophyte $\times$ environment interaction may differ for other abiotic stressors. Lehtonen et al. (2005) reported that endophyte-infected plants grown with high nutrient availability showed higher insect resistance than did those in low-nutrient soils. This would reflect limited synthesis of fungal alkaloids in host plants grown in nitrogen-poor soils (Lehtonen et al. 2005; Cheplick and Faeth 2009). Conversely, evidence shows that low water supply may either elevate (Arachevaleta et al. 1989; Eerens et al. 1998) or have no effect on (Bultman and Bell 2003; Faeth 2009) alkaloid levels. Here, the reduction in shoot growth of drought-stressed plants (fig. 3) might have increased tissue concentrations of secondary metabolites, including lolines and flavonoids (Omacini et al. 2009; Ponce et al. 2009), which can work as insect deterrents (Malinowski and Belesky 2000). Alternatively, reduced growth could lead to higher nutrient concentrations and increased insect herbivory on water-stressed plants (Hale et al. 2003). However, we did not detect significant changes in foliar $\mathrm{N}$ or P levels across treatments. Clearly, more work is needed to reveal the mechanisms whereby different abiotic stresses interact with endophyte infection in modifying host resistance to insect herbivory.

\section{Conditional Outcome of Endophyte-Grass Symbioses}

Herbivory and water stress acted synergistically in altering plant reproductive output (fig. 2), indicating that endophyte mediation of herbivory tolerance could not be isolated from the abiotic context (Wise and Abrahamson 2005). When exposed to aphids, well-watered $\mathrm{E}+$ plants produced $20 \%$ less flowering culms than did E- conspecifics, despite aphid densities being similar on both plant types. Thus, endophyte presence decreased herbivory tolerance under high resource levels. This result adds to the growing view that fungal endophytes do not always effectively protect their host grasses from the impact of herbivorous consumers (Saikkonen et al. 1998; Faeth 2002; Cheplick and Faeth 2009). Furthermore, Bultman et al. (2004) suggested that endophyte-induced herbivore resistance associated with alkaloid production may come at the cost of reduced tolerance to actual herbivory. The energy costs of hosting an endophyte may add to those of herbivory, and if both of these effects are not counteracted by increased herbivore resistance, then the net outcome for the host plant would be a negative one (Bronstein 1994; Hoeksema and Bruna 2000).

We found that any detrimental endophyte effect on reproductive output was reversed for plants exposed to both herbivory and drought stress. This resulted from E- plants being more susceptible than $\mathrm{E}+$ plants to the combined effects of these stressors (fig. 2). Hence, the endophyte played an overall protective role, which became apparent only in the most stressful conditions (Saikkonen et al. 1998). These results counter those of a recent study in which flowering culm production of endophytic Festuca rubra increased with grazing pressure and nutrient availability in moister sites only (Saona et al. 2010). In our study, the enhanced tolerance of E+ plants to herbivory under drought stress corresponded with their higher resistance to aphid colony growth. However, this greater stress tolerance did not allow $\mathrm{E}+$ plants to outperform their E- conspecifics. This likely reflects the fact that aphids were clearly detrimental to $\mathrm{E}+$ plants under high water supply (fig. 2). Endophyte-induced tolerance to multiple stresses should be important in natural settings, where overlapping physical and biotic forces often act to limit plant growth (Saona et al. 2010). 

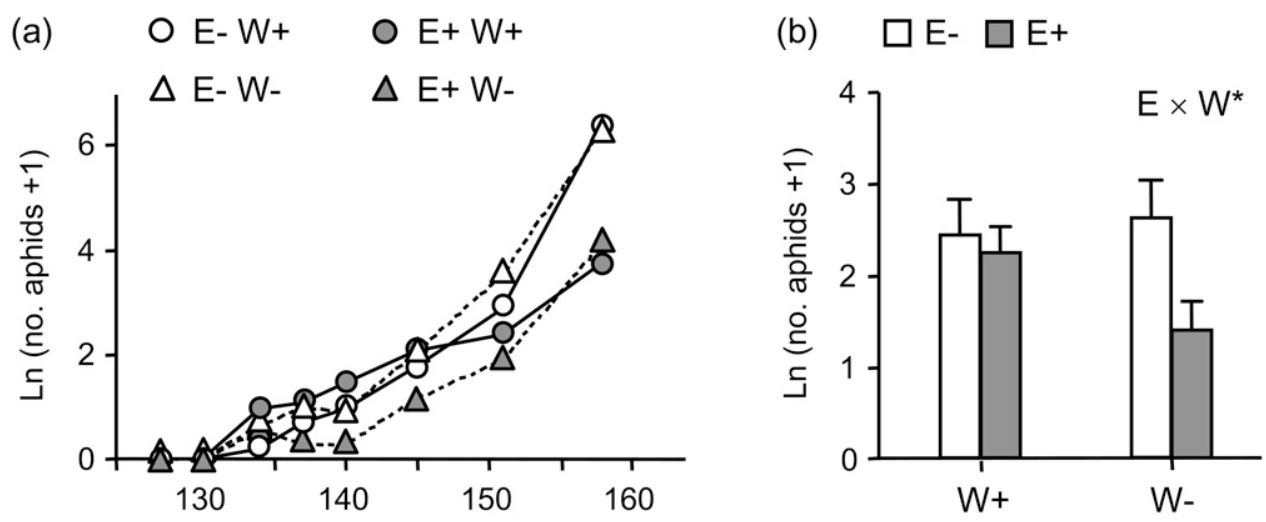

(c)

(d)
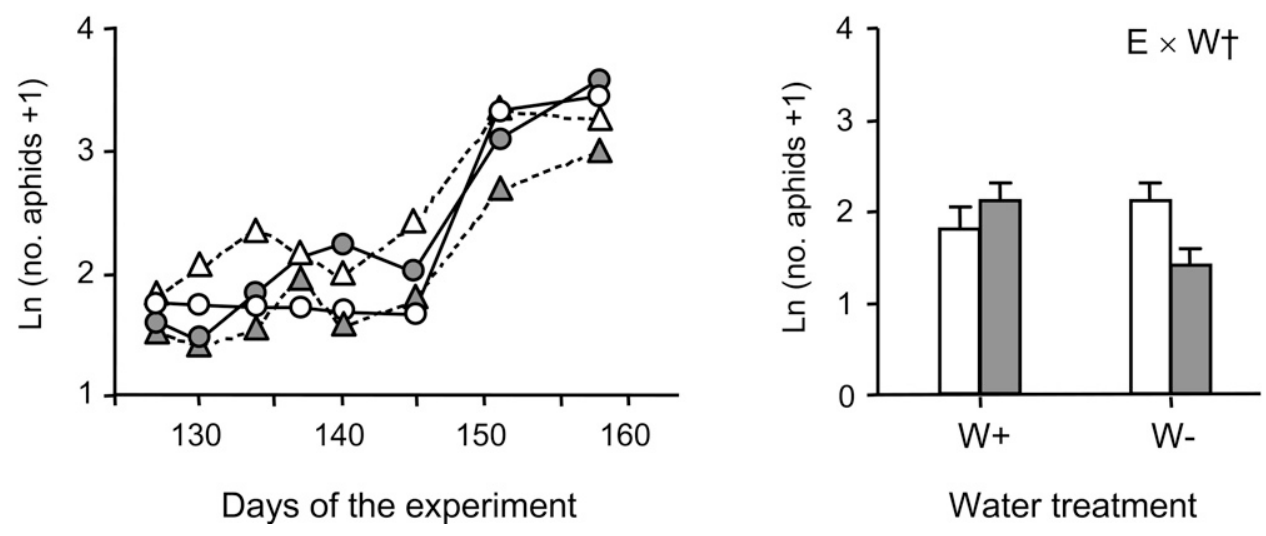

Fig. 4 Effects of endophyte infection and water supply on the population dynamics of two aphid species, Rhopalosiphum padi (a,b) and Sipha maydis $(c, d)$. Lolium multiflorum plants infected $(E+)$ or uninfected $(E-)$ with fungal endophytes were grown under well-watered $(W+)$ or drought $(W-)$ conditions. Data show temporal changes in mean aphid numbers per plant $(a, c)$ and mean aphid densities $(b, d ;+1$ SE; $n=6$ blocks) across census dates. Endophyte $(E) \times$ water $(W)$ interaction: one asterisk indicates $P<0.05$; dagger indicates $P<0.10$.

In sum, we showed that benefits conferred by fungal endophytes increased when host plants were exposed to concomitant biotic and abiotic stressors. Host protection under complex stress regimes may result from direct and indirect endophyte effects associated with abiotic stress tolerance and herbivore resistance, respectively (Clay and Schardl 2002; Müller and Krauss 2005). In this study, however, endophyteinfected plants failed to outperform their uninfected counterparts, regardless of environmental condition. It would therefore be misleading to assume that protective symbioses necessarily provide the host with a net fitness advantage over short ecological time scales (Bronstein 1994; Gundel et al. 2008). Our re- sults support the idea that purported mutualistic endophyte effects may not arise in low-stress environments.

\section{Acknowledgments}

We thank G. Striker for help with the leaf water measurements, M. A. Delfino for checking the aphid species, and P. Gundel, R. Michalet, F. Pugnaire, and two anonymous reviewers for comments on previous drafts of the manuscript. This work was funded by grants from Consejo Nacional de Investigaciones Científicas y Técnicas, Universidad de Buenos Aires, and Fundación Antorchas (Argentina).

\section{Literature Cited}

Ahlholm JU, M Helander, S Lehtimäki, P Wäli, K Saikkonen 2002 Vertically transmitted fungal endophytes: different responses of hostparasite systems to environmental conditions. Oikos 99:173-183.

Arachevaleta M, C Bacon, CS Hoveland, D Radcliffe 1989 Effect of the tall fescue endophyte on plant response to environmental stress. Agron J 81:83-90.

Arnold AE, LC Mejia, D Kyllo, EI Rojas, Z Maynard, N Robbins, EA
Herre 2003 Fungal endophytes limit pathogen damage in a tropical tree. Proc Natl Acad Sci USA 100:15649-15654.

Breen JP 1994 Acremonium endophyte interactions with enhanced plant resistance to insects. Annu Rev Entomol 39:401-423.

Bronstein JL 1994 Conditional outcomes in mutualistic interactions. Trends Ecol Evol 9:214-217.

Bultman TL, GD Bell 2003 Interaction between fungal endophytes 
and environmental stressors influences plant resistance to insects. Oikos 103:182-190.

Bultman TL, GD Bell, WD Martyn 2004 A fungal endophyte mediates reversal of wound-induced resistance and constrains tolerance in a grass. Ecology 85:679-685.

Bush LP, HH Wilkinson, CL Schardl 1997 Bioprotective alkaloids of grass-fungal endophyte symbiosis. Plant Physiol 114:1-7.

Clay K, S Marks, GP Cheplick 1993 Effects of insect herbivory and fungal endophyte infection on competitive interactions among grasses. Ecology 74:1767-1777.

Clay K, CL Schardl 2002 Evolutionary origins and ecological consequences of endophyte symbiosis with grasses. Am Nat 160(suppl):S99-S127.

Cheplick GP 2007 Costs of fungal endophyte infection in Lolium perenne genotypes from Eurasia and North Africa under extreme resource limitation. Envir Exp Bot 60:202-210.

Cheplick GP, SH Faeth 2009 Ecology and evolution of the grassendophyte symbiosis. Oxford University Press, New York.

Cheplick GP, A Perera, K Koulouris 2000 Effect of drought on the growth of Lolium perenne genotypes with and without fungal endophytes. Funct Ecol 14:657-667.

Dahlman DL, H Eichenseer, MR Siegel 1991 Chemical perspectives on endophyte-grass interactions and their implications to insect herbivory. Pages 227-252 in P Barbosa, VA Krischik, CG Jones, eds. Microbial mediation of plant-herbivore interactions. Wiley, New York.

Davitt AJ, M Stansberry, JA Rudgers 2010 Do the costs and benefits of fungal endophyte symbiosis vary with light availability? New Phytol 188:824-834.

de Battista J, N. Altier, DR Galdames, M Dall'Agnol 1997 Significance of endophyte toxicosis and current practices in dealing with the problem in South America. Pages 383-388 in CW Bacon, NS Hill, eds. Neotyphodium/grass interactions. Plenum, New York.

Eerens JPJ, RJ Lucas, S Easton, JGH White 1998 Influence of the endophyte (Neotyphodium lolii) on morphology, physiology, and alkaloid synthesis of perennial ryegrass during high temperature and water stress. N Z J Agric Res 41:219-226.

Faeth SH 2002 Are endophytic fungi defensive plant mutualists? Oikos 98:25-36.

- 2009 Asexual fungal symbionts alter reproductive allocation and herbivory over time in their native perennial grass hosts. Am Nat 173:554-565.

Faeth SH, TL Bultman 2002 Endophytic fungi and interactions among host plants, herbivores, and natural enemies. Pages 89-123 in $\mathrm{T}$ Tscharntke, BA Hawkins, eds. Multitrophic level interactions. Cambridge University Press, Cambridge.

Faeth SH, TJ Sullivan 2003 Mutualistic asexual endophytes in a native grass are usually parasitic. Am Nat 161:310-325.

Gundel PE, WB Batista, M Texeira, MA Martínez-Ghersa, M Omacini, CM Ghersa 2008 Neotyphodium endophyte infection frequency in annual grass populations: relative importance of mutualism and transmission efficiency. Proc R Soc B 275:897-905.

Hahna H, MT McManus, K Warnstorff, BJ Monahan, CA Young, E Davies, BA Tapper, B Scott 2008 Neotyphodium fungal endophytes confer physiological protection to perennial ryegrass (Lolium perenne L.) subjected to a water deficit. Environ Exp Bot 63:183-199.

Hale BK, JS Bale, J Pritchard, GJ Masters, VK Brown 2003 Effects of host plant drought stress on the performance of the bird cherry-oat aphid, Rhopalosiphum padi (L.): a mechanistic analysis. Ecol Entomol 28:666-677.

Hartley SE, AC Gange 2009 Impacts of plant symbiotic fungi on insect herbivores: mutualism in a multitrophic context. Annu Rev Entomol 54:323-342.

Herms DA, WJ Mattson 1992 The dilemma of plants: to grow or defend. Q Rev Biol 67:283-335.
Hesse U, W Schöberlein, L Wittenmayer, K Förster, K Warnstorff, W Diepenbrock, W Merbach 2005 Influence of water supply and endophyte infection (Neotyphodium spp.) on vegetative and reproductive growth of two Lolium perenne L. genotypes. Eur J Agron 22:45-54

Hoeksema JD, EM Bruna 2000 Pursuing the big questions about interspecific mutualism: a review of theoretical approaches. Oecologia 125:321-330.

Johnson NC, JH Graham, FA Smith 1997 Functioning of mycorrhizal associations along the mutualism-parasitism continuum. New Phytol 135:575-585.

Kannadan S, JA Rudgers 2008 Endophyte symbiosis benefits a rare grass under low water availability. Funct Ecol 22:706-713.

Krauss J, SA Härri, L Bush, R Husi, L Bigler, SA Power, CB Müller 2007 Effects of fertilizer, fungal endophytes and plant cultivar on the performance of insect herbivores and their natural enemies. Funct Ecol 21:107-116.

Kuldau G, C Bacon 2008 Clavicipitaceous endophytes: their ability to enhance resistance of grasses to multiple stresses. Biol Control 46:57-71.

Lehtonen P, M Helander, K Saikkonen 2005 Are endophyte-mediated effects on herbivores conditional on soil nutrients? Oecologia 142: 38-45.

Malinowski DP, DP Belesky 2000 Adaptations of endophyte-infected cool-season grasses to environmental stresses: mechanisms of drought and mineral stress tolerance. Crop Sci 40:923-940.

Meister B, J Krauss, SA Härri, MV Schneider, CB Müller 2006 Fungal endosymbionts affect aphid population size by reduction of adult life span and fecundity. Basic Appl Ecol 7:244-252.

Moon CD, B Scott, CL Schardl, MJ Christensen 2000 Evolutionary origins of Epichloë endophytes from annual ryegrasses. Mycologia 92:1103-1118.

Morse LJ, TA Day, SH Faeth 2002 Effect of Neotyphodium endophyte infection on growth and leaf-gas exchange on Arizona fescue under contrasting water availability regimes. Environ Exper Bot 48:357-268.

Müller CB, J Krauss 2005 Symbiosis between grasses and asexual fungal endophytes. Curr Opin Plant Biol 8:450-456.

Omacini M, EJ Chaneton, L Bush, CM Ghersa 2009 A fungal endosymbiont affects host plant recruitment through seed- and litter-mediated mechanisms. Funct Ecol 23:1148-1156.

Omacini M, EJ Chaneton, CM Ghersa, CB Müller 2001 Symbiotic fungal endophytes control insect host-parasite interaction webs. Nature 409:78-81.

Ponce MA, MJ Bompadre, R Erra-Balsells, JM Scervino, JA Ocampo, EJ Chaneton, AM Godeas 2009 Flavonoids, benzoic acids and cinnamic acids isolated from shoots and roots of Italian ryegrass (Lolium multiflorum Lam.) with and without endophyte association and arbuscular mycorrhizal fungi. Biochem Syst Ecol $37: 245-253$.

Rodriguez RJ, JF White, AE Arnold, RS Redman 2009 Fungal endophytes: diversity and functional roles. New Phytol 182: 314-330.

Rudgers JA, AJ Davitt, K Clay, PE Gundel, M Omacini 2010 Searching for evidence against the mutualistic nature of hereditary symbioses: a comment on Faeth. Am Nat 176:99-103.

Saikkonen K, SH Faeth, M Helander, TJ Sullivan 1998 Fungal endophytes: a continuum of interactions with host plants. Annu Rev Ecol Syst 29:319-343.

Saikkonen K, P Wäli, M Helander, SH Faeth 2004 Evolution of endophyte-plant symbioses. Trends Plant Sci 9:275-280.

Saona NM, B Riber Albrectsen, L Ericson, DR Bazely 2010 Environmental stresses mediate endophyte-grass interactions in a boreal archipelago. J Ecol 98:470-479.

Smith SE, DJ Read 1997 Mycorrhizal symbiosis. 2nd ed. Academic Press, San Diego, CA. 
Sugawara K, T Inoue, M Yamashita, H Ohkubo 2006 Distribution of the endophytic fungus, Neotyphodium occultans in naturalized Italian ryegrass in western Japan and its production of bioactive alkaloids known to repel insect pests. Grassl Sci 52: 147-154.

Swarthout D, E Harper, S Judd, D Gonthier, R Shyne, T Stowe, T Bultman 2009 Measures of leaf-level water-use efficiency in drought stressed endophyte infected and non-infected tall fescue grasses. Environ Exp Bot 66:88-93.

TePaske M, R Powell, S Clement 1993 Analyses of selected endophyte-infected grasses for the presence of loline-type and ergot-type alkaloids. J Agric Food Chem 41:2299-2303.

Uchitel A, M Omacini, EJ Chaneton 2011 Inherited fungal symbi- onts enhance establishment of an invasive annual grass across successional habitats. Oecologia 165:465-475.

Vila-Aiub MM, PE Gundel, CM Ghersa 2005 Fungal endophyte infection changes growth attributes in Lolium multiflorum Lam. Aust Ecol 30:49-57.

West C, E Iszekor, K Turner, A Elmi 1993 Endophyte effects on growth and persistence of tall fescue along a water-supply gradient. Agron J 85:264-270.

White JF, MS Torres, eds 2009 Defensive mutualism in microbial symbiosis. CRC, Boca Raton, FL.

Wise MJ, WG Abrahamson 2005 Beyond the compensatory continuum: environmental resource levels and plant tolerance of herbivory. Oikos 109:417-428. 


\section{Queries}

Q1 Is “ 95\%” correct here (from "c.95\%")?

Q2 Please provide the names of the individual(s) (including initials of given names) who had the "personal observation" mentioned here.

Q3 Is "least significant difference" correct for LSD here and in the legend of figure 2?

Q4 Is $0.32 \mathrm{~g}$ vs. $0.26 \mathrm{~g}$ correct here (originally there was no unit of measurement). Similarly, below, is $0.27 \mathrm{~g}$ vs. $0.32 \mathrm{~g}$ correct?

Q5 Is "and this effect strengthened with time as aphid population size overshot on E- plants" correct as edited?

Q6 By cf. here do you mean "see" or "compare"? If the former, I will change this to "see" because we prefer to use "cf." as "compare" only.

Q7 See earlier query re: cf. - Do you mean "compare" or "see"? 